\title{
IKO-IKO SEBAGAI MEDIA PEMBELAJARAN DALAM LINGKUNGAN MASYARAKAT BAJO DI DESA BOKORI KECAMATAN SOROPIA KABUPATEN KONAWE ${ }^{1}$
}

\author{
Oleh \\ Adri $^{2}$ \\ H. Anwar ${ }^{3}$
}

\begin{abstract}
ABSTRAK: Fokus penelitian ini adalah: (1) Apa jenis iko-iko yang ada di lingkungan masyarakat Bajo di Desa Bokori, Keamatan Soropia. (2) Bagaimana fungsi Iko-Iko sebagai media pembelajaran dalam lingkungan masyarakat Bajo di Desa Bokori, Kecamatan Soropia (3) Bagaimana bentuk implementasi Iko-Iko dalam pembelajaran di Desa Bokori Kecamatan Soropia. Penelitian yang bersifat deskriptif kualitatif. Sumber data dalam penelitian ini, berasal dari: sumber tertulis, sumber lisan, dan sumber visual. Prosedur yang digunakan dalam penelitian ini adalah mengacu pada metode sejarah sesuai dengan yang ditulis oleh Sugiono, yaitu: (1) Observasi, (2) Wawancaara, (3) Studi Dokumen. Hasil penelitian menunjukan bahwa: (1) Jenis Iko-iko ada 7: (a) Danring Lao, (b) Anak Koda Lamannang, (c) Babawang, (d) Anak Koda Hasang, (e) Suku Sama/Bajo, (f) Dilao Seheku (laut sahabatku), (g) Dayah nggai lagi darua dolu (ikan tidak sama lagi seperti dulu). (2) Fungsi Tradisi lisan Iko-Iko sebagai media pembelajaran yaitu Tradisi lisan iko-iko menjadi alat masyarakat Bajo untuk mengkonstruksi dan mereproduksi kebudayaannya. Termasuk mengkonstruksi masa depannya dan berkomunikasi dengan orang lain. Tidak mengherankan dalam tradisi lisan Komunitas Bajo dijadikan sarana bersopan santun dalam menyatakan kedermawanan, kebijaksanaan, kerendahan hati, permufakatan, penghargaan, dan kesimpatian. Oleh karena itu, tradisi lisan Komunitas Bajo dapat dijadikan dan dikembangkan sebagai media pembelajaran dalam mengembangkan karakter positif peserta didik. Agar pembelajaran lebih menyenangkan guru dapat menggunakan berbagai media pembelajaran yang inovatif. Menggunakan media dalam pembelajaran tidak hanya berperan sebagai sarana dalam membantu dalam proses pembelajaran akantetapi juga merupakan strategi pembelajaran. (3) Impementasi Iko-Iko dalam pembelajaran yaitu Lewat Iko-Iko ini genarsi suku bajo bisa menjadikannya sebagi pembelajaran ekstrakulikuler karana pembelajaran berbasis budaya bajo blum di terpkan di sekolahsekolah formal oleh karena itu Iko Iko hadir untuk menjawab permasalahnan ini karna meskipun tidak di ajarkan di sekolah formal generasi muda bisa menjumpai bapak M. Jais, bisa belajar tenttang Iko-Iko serta nilai yang terkandung di dalamnya ada bnyak pemebelajaran lewat Iko-Iko di samping regenaris bisa mengetahui tentang budaya Iko-Iko enarasi bajo bisa juga belajar tentang sejarah,tentang kehidupan laut dan lain sebagainya.
\end{abstract}

Kata Kunci: Media, Fungsi, dan pembelajaran

\footnotetext{
${ }^{1}$ Hasil Penelitian

${ }^{2}$ Alumni Jurusan Pendidikan Sejarah

${ }^{3}$ Dosen FKIP UHO
} 


\section{PENDAHULUAN}

Menarik untuk dikaji dalam kaitannya dengan perkembangan Bahasa dan sastra Melayu adalah perdagangan melalui laut yang banyak dimainkan oleh para pedagang Nusantara sejak abad VII M, ditandai dengan tumbuhnya kerajaan-kerajaan Hindu-Budha, kemudian semakin berkembang pada abad XIII sampai dengan abad XVII periode perkembangan agama dan kerajaan-kerajaan Islam hingga menjelang datangnya bangsabangsa Imperialis Eropa di Nusantara. Kurung waktu yang panjang itu pusat perdagangan di Asia Tenggara berada di sekitar Selat Malaka (asal Bahasa/Sastra Melayu). Kekuasaan Sriwijaya atas Selat Malaka baik di Kepulauan Maupun di Semenanjung Melayu antara abad VII-XII, menempatkan Bahasa Melayu sebagai bahasa pengantar dalam perdagangan, politik, dan budaya. Peran tersebut dilanjutkan oleh Kerajaan Melayu di Jambi kemudian pindah di Minangkabau, dan selanjutnya Kerajaan Johor. Pada abad XIV muncul Kerajaan Malaka sebagai pemegang kunci perdagangan dan penyebaran agama Islam di Asia Tenggara, sekali lagi Bahasa dan Sastra Melayu memegang peranan penting dalam setiap aktivitas masyarakat dinamis yang melakukan aktivitas di kawasan Nusantara dan Semenanjung Melayu.

Pada periode tersebut para pedagang Nusantara terlibat dalam perdagangan internasional seperti Cina, India, Philipina, Australia, dan bahkan sampai di Madagaskan Afrika Selatan (Moehadi, 1986: 195). Aktivitas perdagangan tersebut menguntungkan perkembangan Bahasa dan Sastra Melayu yang merupakan milik masyarakat yang ada di pesisir pantai dan pulau-pulau di sekitar Selat Malaka. Para pelayar niaga yang melakukan kegiatan perdagangan di daerah ini dituntut untuk memahami Bahasa Melayu sebagai pengantar dalam transaksi dagang, maka tumbuh dan berkembanglah Bahasa dan Sastra Melayu sebagai bahasa bisnis, budaya, selanjutnya para pedagang tersebut dalam perjalanan dan transaksi di daerah lain Nusantara termasuk di daerah-daerah pesisir Jawa, Kalimantan, Sulawesi, dan pulau-pulau di Kawasan Timur Nusantara, sampai di Philipina Selatan, tetap menggunakan Bahasa Melayu. Mereka mengembangkan pengetahuan, keterampilan, dan nilai melalui tradisi lisan diantaranya Iko-Iko.

Di setiap pelabuhan ditempatkan perwakilan (Syahbandar), pemangku jabatan ini harus makhir berbahasa Indonesia dan bahasa daerah setempat sebagai alat diplomasi. Peran pedagang Bugis, Buton, Makassar, dan Mandar (BBMM) dalam mentrasformasikan pemakaian Bahasa dan Sastra Melayu di wilayah-wilayah kerajaan pesisir pantai Nusantara dan Asia Tenggara. Sejak abad XVII pelabuhan Makassar menjadi tempat transit barang dagangan dari Kawasan Timur Nusantara untuk selanjutnya ke Barat atau sebaliknya (Hafid, 2005: 6, Zuhdi, 1997:5). Para pedagang BBMM sudah akrab dengan pedagang Melayu, mungkin pula peran Orang Bajo seperti ditulis dalam Lontarak Asal-usul Suku Bajo, yang memiliki banyak persamaan budaya khususnya bahasa dengan suku Laut di Selat Malaka, juga mengakui leluhurnya dari Johor, yang kemudian tersebar di segenap pesisir pantai dan pulau-pulau terpencil di Indonesia, Malaysia, Brunai Darussalam, bahkan sampai di Philipina Selatan, Siam, dan Kamboja.

Suku Bajo tetap konsisten mempertahankan Bahasa dan Sastra Melayu, selain Bahasa Bajo (Hafid, 2003: 214) Masyarakat Bajo memiliki kebanggaan dan kesetiaan pada bahasa dan budayanya. Namun, bahasa dan budaya Bajo tidak diajarkan di sekolah sehingga ada kekhawatiran punah di kemudian hari (Hafid, 2015: 90). Para penutur tradisi lisan yang merupakan satu-satunya alat pelestarian budaya mereka semakin berkurang. Misalnya pelantun Iko-Iko M. Jais yang biasa di panggil puto Ndadi', Si Pelantun Iko-Iko 
(sastra Bajo), Puto Ndadi' terkenal dengan nyanyian Iko-Iko nya yang merupakan cerita tentang Kehidupan sosial Orang Bajo, termasuk masalah sosial yang baru saja terjadi tak lepas dari untaian kata dari Iko-Iko yang ia bawakan. Perkembangan Iko-Iko dari tahun ke tahun mengalami kemunduran (stagnan) bahkan terancam punah. Penutur Iko-Iko yang masih ada saat ini, termasuk di Sulawesi Tenggara sangat terbatas dan bahkan sangat langka. Dengan demikian jika kondisi ini dibiarkan, maka Iko-Iko yang merupakan kebanggaan Masyarakat Bajo akan punah (Hafid, 2012: 3).

Tradisi lisan dapat diartikan sebagai kebiasaan atau adat yang berkembang dalam suatu komunitas tertentu yang di rekam dan diwariskan dari generasi ke generasi melalui bahasa lisan. Dalam tradisi lisan terkandung peristiwa sejarah, adat istiadat, cerita, dongeng, pribahasa, lagu, mantra, nilai moral, dan nilai keagamaan (Hafid 2015:1). Tradisi lisan Iko-Iko sebagai sebuah bentuk warisan budaya nenek moyang banyak mengandung nilai-nilai hidup yang berkualitas. Akan tetapi, tradisi lisan yang dulunya menjadi ciri khas suatu daerah tertentu lambat-laun terlupakan oleh zaman. Sangat disayangkan jika warisan para pendahulu harus hilang tanpa bekas hanya karena para orang tua dan tokoh masyarakat gagal mewariskan nilai-nilai luhur tradisi masyarakat Bajo kepada generasi sekarang.

Dalam konteks persaingan global seperti sekarang ini, perlu dipikirkan langkahlangkah untuk melestarikan tradisi lisan Iko-Iko kepada generasi emas pewaris kebudayaan. Minimal ada tiga langkah yang perlu dilakukan untuk mempertahankan hubungan antara masyarakat dengan nilai-nilai tradisinya. Pertama, inventarisasi. Kegiatan ini mencakup pemilahan nilai-nilai luhur yang cocok untuk menghadapi tantangantantangan yang datang menerjang kebudayaan lokal Bajo. Dengan demikian, masyarakat Bajo, diharapkan memiliki posisi tawar dan perisai budaya ketika tantangan datang. Kedua, redefinisi yang mengacu kepada upaya membuat teks (nilai tradisi) itu mempunyai konteks dengan zaman sekarang, yaitu masyarakat Bajo yang berpikiran maju, bukan sekadar Bajo yang berkutat dengan nilai-nilai tradisi tanpa terdorong menatap nilai-nilai masa depan. Ketiga, revitalisasi, sebagai upaya yang terencana, sinambung, dan diminati agar nilai-nilai budaya itu bukan hanya dipahami oleh para pemiliknya, tetapi malah membangkitkan segala wujud kreativitas dalam keseharian dan dalam menghadapi berbagai tantangan.

Melalui upaya revitalisasi, maka domain-domain kebudayaan perlu dikaji ulang dan diberi fungsi baru, tafsir baru termasuk tradisi lisan dalam masyarakat Bajo, sehingga dapat menjadi instrument dalam upaya peningkatan kualitas sumber daya manusia dalam kompetisi global masa depan.Sejatinya tradisi lisan Iko-Iko dapat menjadi kekuatan kultural dan salah satu sumber utama yang penting dalam pembentukan identitas dan membangun peradaban. Tradisi lisan telah berkembang di Indonesia sebelum masyarakat Indonesia mengenal aksara. Pada awalnya tradisi lisan tumbuh subur dan berkembang di seluruh Nusantara, sehingga menjadi salah satu kekayaan budaya masyarakat Indonesia. Setelah aksara masuk ke Nusantara, tradisi lisan tidak hilang, tetapi berkembang beriringan dengan tradisi tulisan. Berbagai pengetahuan dalam tradisi lisan yang secara turun-temurun disampaikan secara lisan yang mencakup tidak hanya cerita rakyat, mitos, dan legenda, tetapi juga dilengkapi dengan sejarah, hukum adat, dan pengobatan. Makna yang terkandung dalam suatu tradisi lisan adalah fenomena kontemporer dan tradisi dalam suatu masyarakat yang merupakan warisan nenek moyang. Hal-hal yang tercakup dalam tradisi lisan seperti sastra, budaya, dan sejarah.

Tradisi lisan tentu tidak akan lepas dari sastra yang mengandung nilai estetika. Tradisi lisan juga erat kaitannya dengan budaya karena berhubungan dengan masyarakat dan kebudayaan di suatu daerah. Tradisi lisan juga terkait dengan sejarah, karena 
merupakan hal yang diwariskan secara turun-temurun. Konteks tradisi lisan berhubungan dengan masa lalu atau sejarah suatu daerah. Sastra lisan merupakan salah satu bagian dari tradisi lisan. Sastra lisan disebarkan dari satu orang ke orang lain secara lisan kemudian prosesnya dilihat, didengar, kemudian dilisankan kembali. Jadi, yang dilihat dalam tradisi lisan adalah proses dan hasil melisankan.

\section{METODOLOGI PENELITIAN}

Sesuai dengan judul penelitian ini maka yang menjadi tempat atau lokasi penelitian ini adalah Desa Bokori Kecamatan Soropia Kabupaten Konawe. Adapun waktu penelitian ini dilaksanakan pada bulan November 2018 sampai dengan Januari 2019. Jenis penelitian ini adalah penelitian sejarah yang bersifat deskriptif kualitatif. Pendekatan yang digunakan dalam penelitian ini adalah pendekatan arkeologis karena penulis memperoleh data-data berdasarkan yang ditinggalkan dan informasi yang di dapat dari informan serta buku.

Sumber data yang digunakan dalam penelitian terbagi dalam tiga kategori sumber sejarah, yaitu pertama, Sumber tertulis yaitu data yang diperoleh dari telaah buku-buku atau literature, skripsi, arsip dan sumber-sumber tertulis lainnya. Sumber-sumber tersebut diperoleh di perpustakaan Universitas Halu Oleo, perpustakaan Fakultas Keguruan dan Ilmu Pendidikan dan perpustakaan wilayah Sulawesi Tenggara serta kantor Desa Bokori. $K e d u a$, sumber lisan yaitu sumber data yang diperoleh melalui keterangan lisan atau hasil wawancara dengan informan yang mengetahui dan bisa memberikan gambaran tentang Iko-Iko Sebagai media Pembelajaran Dalam Lingkungan Masyarakat Bajo Di Besa Bokori Kecamatan Soropia Kabupaten Konawe. Ketiga, sumber Visual, yaitu data yang diperoleh melalui hasil pengamatan secara langsung yang berkaitan dengan penelitian ini

Kemudian prosedur dalam penelitian ini menggunakan metode Sugiyono, (2016: 312) yang terdiri dari tiga tahapan, yaitu: (1) Observasi, (2) Wawancara (3) studi dokumen. Prosedur ini pada dasarnya sama saja dengan prosesur penelitian sejarah lainnya dengan asumsi data-data yang diperoleh dalam penelitian ini benar-benar dapat dipertanggung jawabkan.

\section{HASIL DAN PEMBAHASAN}

\section{Jenis Iko-Iko}

Iko-Iko ini sering digunakan oleh masyarakat Bajo ketika hendak menidurkan anaknya, dinyanyikan pada saaat berlayar, serta selalu ditampilkan dalam kegiatan budaya. Adapun Jenis tersebut adalah sebagai berikut:

1) Danring lao;

Iko-Iko ini menceritakan Si denring lao yang menayakan kepada ibu nya dimana ayahnya berada, setelah dia mengetahui bahwa ayahnya pergi belayar meninggalkanya ketika dia masih sangat kecil, kemudian memutuskan untuk mendatangi tanttenya, Si kaca kamummu. Lanjut cerita Sidenring Lau menikah dengan Si kaca kamummu, karena begitu ramainya pesta itu, tujuh hari tujuh malam acaranya. (Pelantun Iko-Iko, M. Jais/puto Ndadi, Wawancara, 9 Januari 2019). Adapun bunyi iko-iko tersebut adalah:

Eee bele sanang si Danring lao, O masi ya daaka dampala nadipalenang ele uwwa na lama" kapulau-pulau jawa bele, allau basar ne sanang iyya patilawangna ne ka mma na, oo bele sanang mma mangga sanang uwwaku bele, Oo yo, mma na sanang Oo Danring lao masiko daaka dampala bonu di palenang lama, ele uwwanu kapulau-pulau jawa bele,... 
"Artinya: Sidenring lau, masih satu jengkal satu jari sudah di tinggalkan oleh bapaknya, pergi ke pulau jawa pergi berdagang lamanya dua puluh tahun, lahirlah si denring lau, dia sudah besar dan menyakan bapaknya. Katanya, hai ibuku, dimankah bapakku? Ibunya menangis dan menjawab: wahai anakku si denring lau: sejak masih kecil ananda satu jengkal satu jari anada di tinggalkan oleh bapakmu yang merantau ke pulau Jawa....

\section{Anak koda lamannang}

Iko-Iko ini menceritakan kisah seorang anak yang pergi ziarah kubur ketempat ayahnya meninggal, karna penasaranya, dia tidak mendengar himbauan bahwa akan ada angin kencang yang akan menipa lokasi temapat ayahnya sering memancing ikan cakalang. Hingga ia hanyut dan tidak di temukan. Penggalan bunyi iko-iko in I adalah

"Oo bele sanang ana, koda lamannang masi ya daaka dampala na di palenang matai ale uwwa na ma timpusu turingah boyo uwwa na sanang oo allau bona tilau ka mmna oo bele sanang mma manggako atoaku lilla bona nanges sanang mma na udaya ma nanges bona baong ne ka ana, koda lamannang oyo, na ana, koda lamannang oo masi ko daaka dampala,...

Artinya; Ooo, kasian Anak Koda Lamannang, masih satu jengkal, satu jari sudah di tinggal mati oleh ayahnya, di laut tempat mancing ikan cakalan, setelah besar Anak Koda Lamannang bertanya kepada ibunya tentang keberadaan ayahnya katanya: wahai ibuku dimanakah bapakku?,....

\section{Babawang}

Iko-Iko ini menceritakan tentang kehidupan si Babawang yang tidak lagi melaut karna keadan angin kencang. Dari itu si Babawang berpersan kepada generasinya, kepada Anak-anaknya, Cucu-cucunya agar bersekolah, karna lewat itu kita bisa merubah masa depan kita, kita harus punya pengetahuan agar kita tidak sama lagi dengan mereka. Pesan moral yang terkandung dalam Iko-Iko ini sangatlah membangunkan motivasi setiap pembaca, dan pendengarnya. Besar harapan kiranya kita bisa memberikan semngat, memberikan pandangan kepada generasi Anak suku Bajo bahwa pendidikan itu penting untuk mengarungi kehidupan di era Globalisai saat ini. Adapun bunyinya adalah

Eee bele sanang si Babawang sanang Oo yo,na Oo ainekotu na kalulumang ta lamung darua batittu ngiri, ne sangai di tare, ne memong pammanang bele allau iyya ne sanang bona nia baongku allau dahalagi sanang kang darua ana,-ana, ku mpuku tabulos ne kami yo,na bele ma makarissa iya singsara itu dahalagi kaang bele allau iyya ne sanang na nia pasang atoa ta daulu yo,na bo sikola neko kang barah nia jee kalullumang di dahalagi singsara darua kami, bele ma mamia ka dilao, sanang apa, darua ko yo,na tikkaku ne memong bele pulau si tonda-tonda sapa, si koe,-koe ma mamia kalulumang ka dilao bele.

Artinya: Eee kasian si Babawang, Katanya apami ini kalau begini, kencang me angin, ditarik semua perahu kedarat, tidak bisa mencari kehidupan/kalullumang kasian, makanya pesanku kepada kalian, jangan ikuti bapak mu ini, kalian dengar pesan ini Anak-anak ku, cucu-cucu ku, biarkan kami yang terlanjur merasakan penderitaan ini, makanya ada pesan orang tua kita supaya kalian Sekolah dan mempunyai masa dapan supaya jangan lagi seperti kami, yang setiap harinya mencari kelaut, saya sudah berlayar menyusuri pulaupulau mencari kehidupan/kalullumang(Pelantun: M. Jais/Puto Ndadi, Wawancara, 11 Januari 2019).

\section{Anak koda Hasang}

Ooo bele sanang ana, koda hasang ele kaporeang na bele sanang ana, koda hasang nggai ya tambbang madara, mampaputar ma tarusang sanang bele allau duduangang na je ka mbo panai ma palipu, ma mia kappal balanda bele bona mono manusia na bona 
ngala ayyaina bele sanang iya ne iru pugaina kallulumang ale ana, koda hasang bele allau ana, di papalaku te bele ele mma na baka uwwana sanang nggai nia ana,na te yo,na sanang bele poro di bunang je kita bijja bele missa meta pore na madiata lino itu sanang, allau bo lahir ne ana, koda hasang pangarang na iyya sanang.

Artinya: Ooo kasian anak koda Hasang lantaran jagonya, Anak koda Hasang tidak tinggal di darat, dia berputar-putar di lautan kasian, dia berdua saja bersama Mbo Panai berputar di lautan Mencari kapal Belanda, kemudian setelah menemukan kapal Belanda, kemudian mereka memukul orang Belanda Tersebut dan mengambil semua milik orang belanda yang ada di kapal, hal ini yang menjadi mata pencarian Anak koda Hasang, anak koda Hasang ini adalah anak yang di Minta-minta dalam Daa Ibu dan Bapaknya sebelum mereka punya anak si Koda Hasang, Dalam doanya ibu Koda Hasang Berdoa: Mudamudahan diberi anak yang gagah perkasa lagi pemberani tidak ada sainganya diatas bumi ini, setelah anak itu lahir di beri lah nama Anak Koda Hasang.(Pelantun, M. Jais/Puto Ndadi, Wawancara 11 Januari 2019).

Iko-Iko diatas menceritakan tentang keberanian Koda Hasang dalam mencari serta melawan orang belanda, di satu sisi bisa disebut patriot, disisi lain adalah seorang bajak laut, karena dia tidak mempunyai pekerjaan lain melainkan mencari kapal belanda untuk diambil barangnya inilah keberanian koda Hasang.

\section{Suku Sama (Suku Bajo)}

Allau bele sanang asala usul na sama bele allau mata tummu ma kampoh bajoe allau bona pore sanang tikka ma bugis nyari bilana tummuna ne bolo dangoa bele sanang pasa ma dialang bilana bona niba iyya yo,na aikotu tullu ngilau ne bila ku nggai isiang jara bolo itu je ma palimba,-limba sanang kabila itu bona moa ya mole nagu iyya madia ruma na sanang sukku na amombo, iru nggai nia ana,na allau tinnga bangi sanang takuda ne ndana yo,na Obatong lalo kita sanang aikoru nia leh ananna, nanges bele bona batong lla na bona nanju iya ka dia ruma na ma bolo ma isiang bilana bona mila bolo ananna bele ma dialang na sanang allau ele kasukurangna sanang marannuna manummu ananna iru bele bona ananna dinda iyya ma basar ne katonangna ne ale datu pandana ne bele.

Artinya; Asal usulnya Bajo yang di temukan di Tanah Bajoe, pada siang hari datang dari seorang laki-laki dari suku Bugis, pergi memeriksa Seronya, ia mendapatkan tumpukan bambu, kasian bambu itu masuk dalam seronya, kemudian bambu itu ia kelurkan dan berkata lah dia: apami ini kasian sudah 3 hari seroku tidak berisi, hanya bambu-bambu ini yang saya temukan setiap kali saya masuk seroku, kemudian ia membawa bambu itu pulang dan menyimpanya di bawah rumahnya, si bapak ini sudah lama menikah tapi tidak punya anak. Pada malam harinya si istri terbangun karna mendengar tangisan seorang bayi, kemudian ia membangunkan suaminya katanya: saya mendengar suara tangisan seorang bayi, setelah itu suaminya langsung bangun dan melihat ke bawah rumahnya tempat ia menyimpan bambu yang ia temukan, karna penasaran dia membelah bambu itu dan menemukan seorang anak permpuan didalamnya. Si bapak sangat senang sekali karna memang dia tidak punya anak, setelah anak itu tumbuh dewasa samapailah informasi kepada raja bahwa ada anak permpuan cantik disana katanya, kemudian sang raja langsung menjadikan si anak permpuan tersebut menjadi istrinya. (Pelantun: M. Jais/Puto Ndadi, Wawancara, 12 Januari 2019).

Iko-Iko diatas menceritakan asal usul suku Bajo yang ditemukan dari sekumpulan bambu yang masuk ke sero seorang nelayan bugis, yang katanya dari tanah Bajoe, lanjut cerita anak ini tumbuh menjadi perempuan yang sangat cantik karna kecantikanya sang raja pada saat itu menjadikannya sebagai soerang istri. 


\section{Dilao Seheku (Laut Sahabatku)}

Danakang pakale-pakale kang lilla sama ma nia ma iga, bae amadara sanang, na kita sama-samako bele lilla bajo maikang bota merhatikan iyya sanang isina dilao iru, dahalagi ne simata-mata timba,-timba ta liwa, ka bbong kao lilla bajo. Kale di ne iru n ia ne bagai tikka madara nia ne maraang kita, malesso kapah lamong piara ta ne lingkungan ta, ma nia maduilao lamong anu rosa, pakiala, ta kalau lilla bajo calelle, lilla sama celle. Ndi karena kita sanang anu di larangang kita makkaraha, isina madilao,bona simata kita ma takatonang ma nimba, padahal kita dangai ne manusia sanang mamaraang kita, lamong takole takatonang anu di katalawang iru na kayana sumata masi nia bagai na mangaru kita napore nimba, lilla sama, bo mandiru ne salana pangatonang lilla sama ee calelle, dadi uwwa pakiala, ne sanag kita dahalagi kita matappa lamong yo, sama iru na pore nimba, sama iru nggai lagi biasa nimba karena talau ne mapamarenta baik ma polisina kaang lilla sama. Iyya ne sanang bona nia pabaong ku bona nia pamaraku, pakikiale kang danakag sama dahali pugai di malesso kapah lamong nia ka ketua di, bo dibaong malaku ainama jama di asal dahalagi panimbakang karena iru anu di larangang ko bele kau ele pamarenta ooo lilla sama.

Artinya: Saudara Dengarlah kalian laki-laki Bajo yang ada di samping, baik yang di darat karena kita semua suku sama/ bajo. Mari kita perhatikan isi yang ada dilaut, janga hanya semata mata hanya di Bom dan di Bom, Dengar lah itu, sudah ada bagai (Non Bajo? Diluar Suku Bajo) dari darat meberitahuakan kita, alangkah baiknya kalau kita pelihara lingkungan kita, yang ada di laut, kalau ada yang rusak kita perbaiki.Karena kita dilarang merusak isi laut, kita (Suku Bajo) yang ditahu merusak dengan mengunakan Bom padahal sudah berapa orang yang memberitahukan, hal itu ditahu karena sangat menetukan mengunakan Bom. Seperti itulah keadaanya masih ada bagai (Non Bajo/di luar Suku Bajo) yang mempengaruhi kita untuk pergi membom, disitulah letak kesalahan pemahaman kita.Jadi, Bapak dengarkanlah, jangalah percaya kalau orang Bajo itub pergi membom, orang bajo itu tidak lagi biasa membom, karena mereka takut dengan pemerintah, baik polisi dan lainya. Itulah sehingga ada perkataanku, dengarlah saudaraku suku Bajo, Janganlah melakukan lagi, alangkah bagusnya kalau kalian datang ke Ketua/Punggawa/Pemerintah, baru kalian menyampaikan apa yang akan kalian kerjakan, asal jangan lagi melakukan pengeboman ikan karena itu dilarang oleh pemerintah, usulkan lah apa yang akan kalian kerjakan. (Pelantun: M. Jais/puto Ndadi, Wawancara, 9 Januari 2019).

Iko-Iko diatas menceritakan tentang ajakan terhadap suku Bajo untuk menjaga laut, laut adalah sahabat, laut adalah segalanya bagi Suku Bajo, sehingga perlu dijaga dan tidak merusaknya, sebagaimana angapan dari orang lain yang mengatakan bahwa Suku Bajo adalah prusak laut. Kerifan budaya Bajo adalah cermin mereka bersahabat dengan alam.

\section{Dayah nggai lagi darua Dolu (Ikan tidak sama lagi seperti dulu)}

Eee di tarek ne pamannang, ngiri, ne sangai, nggai lagi na takole mamera doi, mamea kalullumang bele sanang. Daha du kariddang sukar daha du sanang kariddang marennu, daha du karidaang lamung darua batittu,ansisni kami ma pore kadilao, dayah dayah dantolo duantolo sanang matakole bele, lamung batitu ngai lagi ginna na di pugai ongkos maruma bele sanang, Ee ailagi nama boa ana,na sikola napa balanja loamong dalle mimitta rua singo, sanang oooo bele ,,allaw mamaia kita darua dolu, nggai lagi na darua ,nggai lagi na nia sanang ,apa, dayah nggai lagi para sanang ma dilao, nggai lagi darua 
dolu pallibu kita masi je kole na si karapi kalullumang. Ooo aine itu lamong batittu dayah nggai lagi para, lamo missi nggai lagi para takole sanang, nggai lagi darua dolu.

Artinya: Eee ditarik ke darat perahu tempat mencari, angin sudah bertiup,tidak bisa lagi mencari uang, mencari kehidupan, Eee biar kita susah, jangan terlalu gembira,jangan terlalu sedih, kalau seperti begini kami mencari kelaut, ikan setusuk dua tusuk yang kami dapat. Eee kalau begitu tidaklah cukup ongkos di rumah. Eee apa lagi yang akan di bawa anak ke sekolah untuk belanja, kalau rejeki menetes seperti air keringat. Kalau kita mencari seperti dahulu kala, tidak akan di dapat lagi, karena ikan sudah tidak banyak di laut, tidak lagi seperti dulu kalau melaut masih bisa menyambung hidup.

Ooo apa jadinya kalau begini,ikan sudah tidak banyak, kalau memancing tidak lagi banyak ikan di dapat, bukan lagi seperti dulu.(Pelantun: M. Jais/Puto Ndadi,Wawancara, 11 Januari 2019).

Iko-Iko diatas menceritakan bagaimana perubahan cuaca dan iklim menyebabkan perubahan kehidupan bagi suku Bajo, penghasilan semakin berkurang sehingga mengancam kelangsungan pendidikan anak-anak Bajo karena kurangnya penghasilan dari orang tua yang melaut.

\section{Fungsi Tradisi Lisan Iko-Iko sebagai Media Pembelajaran}

Perkembangan tradisi lisan Iko-Iko dalam kehidupan masyarakat, merupakan perwujudan dari usaha dan cara-cara kelompok tersebut dalam memahami serta menjelaskan realitas lingkungannya, yang disesuaikan dengan situasi alam pikiran masyarakat di suatu zaman tertentu. Alam pikiran masyarakat yang dipandang sebagai lahan paling subur bagi berkembangnya pemikiran seperti itu. Cara masyarakat menjelaskan atau memahami realitas seperti itu, bukan merupakan suatu kesengajaan untuk mengacaukan fakta dengan khayalan, tetapi memang merupakan suatu cara dalam menangkap realitas sesuai dengan alam pikiran mereka. Oleh karena itu, tradisi lisan dalam suatu masyarakat bisa beragam bentuknya, tergantung masyarakat yang mendukungnya.

Berbeda dengan kondisi dalam komunitas Bajo yang nyaris mengabaikan upaya pelestarian dan pengembangan tradisi lisannya, untuk mengairahkan kembali keberadaan Iko-Iko di tengah-tengah masyarakat Bajo dan mendorong upaya pelestarian budayanya ini pada masa mendatang, maka perlu ada upaya pelestarian dalam berbagai bentuk seperti: penulisan, festival, yang melibatkan para penutur yang masih ada dalam masyarakat bajo. (Hafid, 2015:90)

Fenomena tersebut, berbeda dengan kondisi kebutuhan belajar masyarakat Bajo yang masih banyak menyandang buta aksara. Mereka dalam pembelajarannya selama ini kurang termotivasi karena para tutor yang mengajar mereka umumnya menggunakan pembelajaran konvensional sebagai mana pembelajaran di sekolah. Sejatinya selama ini tradisi lisan hanya berfungsi normatif, namun dalam perkembangannya dapat berfungsi praktis dan pragmatis pada era modern sekarang. Semua fungisi tradisi lisan tersebut akan dapat mengubah individu ke arah yang lebih berdaya, jika dimanfaatkan dalam proses pembelajaran termasuk dalam pembelajaran keaksaraan fungsional. Menurut (Hafid, 2015:129) Jika potensi sosial budaya yang ada dapat dikelola secara optimal untuk menjadi media dan muatan pembelajaran baik dalam pendidikan formal maupun pendidikan nonformal, maka komunitas Bajo dapat meningkatkan pengatahauan, keterampilan, dan sikap positif baik dalam aspek sosial, maupun dalam penegembangan sumber daya alam sekitarnya.

Tradisi lisan Iko-Iko sebagai folklore menurut (Sibarani, 2013: 26) dapat dijadikan sebagai media dan sumber pendidikan/pembelajaran. Melalui kaca mata yang sama, tradisi 
lisan dapat digunakan sebagai sumber pengetahuan, misalnya melalui ritual Hamis Batar (tradisi lisan masyarakat Timor berupa upacara syukuran terhadap jagung yang dipanen) di Kupang sebagai media untuk memperoleh pengetahuan yang mendekati nilai kebenaran, seperti mengkaji kepercayaan masyarakat setempat terhadap kekuatan di luar diri manusia, tentang fungsi tetua adat sebagai bagian dari sistem sosial yang mengambil peran dalam ritual Hamis Batar. Melalui "pendekatan historis" untuk mendapatkan pengetahuan dari tradisi lisan, kita bisa menemukan pondasi kebudayaan Indonesia, sekaligus dapat digunakan untuk memantapkan identitas kebudayaan nusantara dalam rangka menjawab tantangan zaman.

Tradisi "penuturan" merupakan akar dari budaya yang berkembang di Nusantara. Hal ini dapat diasumsikan melalui masyarakat pra-aksara yang menggunakan tradisi lisan IkoIko untuk menyalurkan cara berpikir dan cara hidup antar sesama manusia, termasuk aktivitas yang berhubungan dengan alam dan sang pencipta. Sehingga, hadirnya tradisi lisan ternyata ikut mendukung lahirnya adat istiadat, kebiasaan, hukum, kepercayaan, maupun bahasa yang berkembang di wilayah-wilayah Indonesia. Seiring dengan perkembanan zaman, tradisi lisan mulai ditinggalkan karena pencitraannya yang kuno dan statis sebagai hasil budaya masa lampau. Hal ini tidak terlepas dari tradisi tulis-menulis yang mulai dikenal, serta adanya pengaruh globalisasi yang serta-merta ikut merubah cara berpikir masyarakat Indonesia. Sehubungan dengan upaya penyelamatan dan pelestarian terhadap akar budaya nusantara, maka diperlukan usaha-usaha membangkitkan ketertarikan kembali terhadap tradisi "penuturan" ini. Usaha-usaha tersebut diantaranya, melakukan aktualisasi tradisi lisan yang dikemas dalam seni pertunjukan, mengikutsertakan tradisi lisan dalam dunia akademis sebagai upaya pengenalan sekaligus melahirkan generasi pewaris tradisi "penuturan", serta menjadikan tradisi lisan sebagai sumber pengetahuan yang dapat dikaji melalui metode ilmiah dan pendekatan displin ilmu sosial, seperti pendekatan historis. Diharapkan tradisi lisan dapat diselamatkan dan dilestarikan keberadaannya ditengah-tengah iklim globalisasi. Sehingga, masyarakat Indonesia memiliki identitas kebudayaan yang kuat agar dapat digunakan sebagai pedoman dalam rangka menyikapi budaya-budaya asing yang masuk ke Indonesia (Hafid, 2015: 4$5)$.

Berdasarkan pemikiran tersebut menunjukkan bahwa tradisi lisan merupakan lambang identitas daerah/komunitas yang diungkapkan lewat bahasa lisan, tradisi, hukum, sejarah yang mengandung nilai-nilai luhur yang sangat berharga (Hafid, 2015:6).Tradisi lisan merupakan suatu aset kekayaan budaya yang berpotensi untuk dikembangkan sebagai bahan ajar bagi masyarakat setempat, sehingga dapat melestarikan nilai dan mengembangkan karakter positif dalam kehidupan bermasyarakat, berbangsa dan bernegara.

Tradisi lisan Iko-Iko menjadi alat masyarakat Bajo untuk mengkonstruksi dan mereproduksi kebudayaannya. Termasuk mengkonstruksi masa depannya dan berkomunikasi dengan orang lain. Tidak mengherankan dalam tradisi lisan Komunitas Bajo dijadikan sarana bersopan santun dalam menyatakan kedermawanan, kebijaksanaan, kerendahan hati, permufakatan, penghargaan, dan kesimpatian. Oleh karena itu, tradisi lisan Komunitas Bajo dapat dijadikan dan dikembangkan sebagai media pembelajaran dalam mengembangkan karakter positif peserta didik. Agar pembelajaran lebih menyenangkan guru dapat menggunakan berbagai media pembelajaran yang inovatif. Menggunakan media dalam pembelajaran tidak hanya berperan sebagai sarana dalam membantu dalam proses pembelajaran akan tetapi juga merupakan strategi pembelajaran.(Risal, Wawancara, 14 Januari 2019). 
Tradisi lisan Iko-Iko ini ditengah-tengah masyarakat kehidupan masyarakat bajo saat ini sudah hampir punah ini dikarenakan banyak generasi selanjunya bahkan tidak mengetahui bagaimana lantunan Iko-Iko itu sendiri. Menurut Nombbo 67 tahun meengatakan bahwa untuk saat ini Iko-Iko masih sering dilantunkan oleh orang tua pada masyarakat Bajo. Peran tradisi lisan Iko-Iko pada masyarakat Bajo pada acara-acara tertentu memiliki makna yang mendalam bagi yang mengadakan acara maupun yang melantunkan Iko-Iko.

Bercerita merupakan aktivitas penting yang perlu dikuasi siswa. Bukan saja siswa senang menyimak cerita, tetapi cerita merupakan salah satu metode pembelajaran seni bahasa tertua. Cerita mendorong anak untuk mencintai bahasa. Dari sebuah cerita, siswa bukan saja dapat mengetahui perkara-perkara baru, tetapi juga dapat meningkatkan minatnya terhadap hal-hal baru .

Nilai pendidikan sangat erat kaitannya dengan karya sastra. Setiap karya sastra yang baik, termasuk cerita rakyat, selalu mengungkapkan nilai-nilai yang bermanfaat bagi pembacanya. Nilai-nilai tersebut bersifat mendidik serta menggugah hati pembacanya. Nilai-nilai pendidikan yang dimaksud dapat mencakup nilai pendidikan moral, nilai adat, nilai agama (religi). Hal ini menunjukkan bahwa nilai sastra berarti kebaikan yang ada dalam makna karya sastra bagi kehidupan. Nilai sastra dapat berupa nilai medial (menjadi sarana), nilai final (yang dikejar seseorang), nilai kultur, nilai kesusilaan, dan nilai agama.(Risal,Wawancara,10 Januari 2019)

Kita menyadari bahwa setiap sistem pendidikan kiranya perlu disertai usaha untuk menanamkan wawasan pemahaman budaya bagi setiap anak didik, Melalui usaha pemahaman budaya dapat ditumbuhkan sikap dan rasa bangga, percaya diri, dan rasa ikut memiliki. Usaha untuk mengenal pribadi dari seseorang terlihat dari cara dalam menanamkan budaya melalui cerita pada nanak-anak, kita mengenalkan cara berpikir, mencontohkan usaha para pendahulu dengan prinsip-prinsip kehidupan, ajaran yang di bawa serta sikap dan perilaku yang diajarkan pada zaman dahulu. Seorang raja akan bersifat sopan dalam tingkah laku karena pendahulunya menurunkan cerita ini pada generasi berikutnya. Secara lebih mendasar dapat dikatakan bahwa pengajaran sastra, yakni cerita rakyat, memiliki banyak manfaat dan dapat membantu pendidikan secara utuh.

Dari beberapa pendapat tersebut menunjukkan bahwa pemilihan tradisi lisan Iko-Iko sebagai media pembelajaran sangat tepat. Dalam jangka pendek, tradisi lisan Iko-Iko dapat digunakan sebagai media yang mempermudah/mempercepat pemahaman warga belajar akan bahan ajar yang tersaji; dan jangka panjang, sebagai bahan pembinaan dan pengembangan apresiasi sastra Indonesia dan daerah, pada masa datang dapat membentuk watak yang kelak akan dapat menciptakan dan mengembangkan inspirasi cipta, rasa dan karsa pada diri peserta didik, dikala krisis moral sedang melanda linkungannya.

\section{Implementasi Iko-Iko dalam pembelajaran}

Untuk itu Nilai-nilai kebudayan Iko-Iko Harus diterpkan melalui pendidikan. Para generasi muda wajib menjadi orang berpendidikan yang bermoral dan berahlak mulia, pendidikan dan budaya harus selaras dan mewujudkan kembali tradisi kehidupan yang saling gotong royong, musyawarah dan melestarikan nilai-nilai budaya Iko-Iko sebagai pembelajaran dan identitas diri. (Parman SE, wawancara 15 Januari 2019). pengetahuan apapun bentuknya, harus mempertimbangkan latar belakang budaya peserta didik

Lewat Iko-Iko ini regenarsi suku bajo bisa menjadikannya sebagi pembelajaran ekstrakulikuler karana pembelajaran berbasis budaya Bajo belum di terpkan di sekolahsekolah formal oleh karena itu Iko Iko hadir untuk menjawab permasalahnan ini karna 
meskipun tidak di ajarkan di sekolah formal regenaris muda bisa menjumpai bapak M. Jais bisa belajar tenttang Iko-Iko serta nilai yang terkandung di dalamnya ada bnyak pemebelajaran lewat Iko-Iko di samping regenaris bisa mengetahui tentang budaya iko-iko regenarasi Bajo bisa juga belajar tentang sejarah,tentang kehidupan laut dan lain sebagainya. (Parman SE, Wawancara, 14 Januari 2019).

Pembelajaran berbasis budaya Iko-Iko merupakan strtegi penciptaan lingkungan belajar dan perncanaan pengelaman belajar yang mengintregasikan Iko-Iko Sebagai bagian dari proses pembelajaran. Pembelajaran berbasis budaya Iko-Iko sebagai bagian yang fundamental (mendasar dan penting) bagi pendidikan sebagai ekspresi dan komunikasi suatu gagasan dan perkembangan pengetahuan.

Pembelajaran berbasis budaya Iko-Iko membuat siswa tidak hanya meniru dan menerima informasi yang di sampaikan tetapi siswa menciptakan makna, pemahaman, mengembangkan pengetahuhan yang diperoleh. Proses pembelajaran berbasis budaya tidak hanya mentransfer budaya Iko-Iko serta perwujudan Iko-Iko tetapi menjadikan siswa mampu menciptkian makna, menembus batas imajinasi, dan kreatif dalam mencapai pemahaman yang mendalam tentang Iko-Iko.

\section{KESIMPULAN}

Berdasarkan hasil Penelitian diatas, maka dengan ini dapat disimpulkan beberapa hal Pertama Jenis Iko-Iko yang sering digunakan oleh masyarakat Bajo d Desa Bokori yaitu: (a) Danring Lao, (b). Anak Koda Lamannang, (c) Babawang (d). Anak Koda Hasang (e). Suku Sama/Bajo. (f) Dilao Seheku (Laut Sahabatku) (g). Dayah nggai lagi darua dolu (ikan tidak sama lagi seperti dulu). Kedua Fungsi Tradisi lisan Iko-Iko sebagai media pembelajaran yaitu Tradisi lisan iko-iko menjadi alat masyarakat Bajo untuk mengkonstruksi dan mereproduksi kebudayaannya. Termasuk mengkonstruksi masa depannya dan berkomunikasi dengan orang lain. Tidak mengherankan dalam tradisi lisan Komunitas Bajo dijadikan sarana bersopan santun dalam menyatakan kedermawanan, kebijaksanaan, kerendahan hati, permufakatan, penghargaan, dan kesimpatian. Oleh karena itu, tradisi lisan Komunitas Bajo dapat dijadikan dan dikembangkan sebagai media pembelajaran dalam mengembangkan karakter positif peserta didik. Agar pembelajaran lebih menyenangkan guru dapat menggunakan berbagai media pembelajaran yang inovatif. Menggunakan media dalam pembelajaran tidak hanya berperan sebagai sarana dalam membantu dalam proses pembelajaran akan tetapi juga merupakan strategi pembelajaran.Ketiga Impementasi Iko-Iko dalam pembelajaran yaitu Lewat Iko-Iko ini regenarsi suku bajo bisa menjadikannya sebagi pembelajaran ekstrakulikuler karana pembelajaran berbasis budaya bajo blum di terpkan di sekolah-sekolah formal oleh karena itu Iko Iko hadir untuk menjawab permasalahnan ini karna meskipun tidak di ajarkan di sekolah formal regenerasi muda bisa menjumpai bapak M. Jais, bisa belajar tenttang IkoIko serta nilai yang terkandung di dalamnya ada bnyak pemebelajaran lewat Iko-Iko di samping regenaris bisa mengetahui tentang budaya Iko-Iko regenarasi bajo bisa juga belajar tentang sejarah,tentang kehidupan laut dan lain sebagainya.

\section{DAFTAR PUSTAKA}

Hafid, Anwar. 2003. Manajemen Pemberdayaan Perempuan: Studi pada Keluarga Nelayan Suku Bajo. Bandung: Alfabeta.

Hafid, Anwar. 2005. "Konsistensi Penggunaan Bahasa Indonesia dalam Perjalanan Sejarah Bangsa Indonesia”. Makalah disajikan dalam Seminar Nasional 

sebagai Bahasa Perhubungan Luas", Kendari 11-13 Oktober 2005.

Hafid, Anwar. 2012. Peran Cerita Rakyat Iko-Iko Berbasis Sastra Melayu Dalam Penguatan Komunitas Etnis Bajo. Makala Disajikan Pada Seminar Internasional Tradisi Lisan Nusantara (VII) Di Tanjungpinang, 23-27 Mei 2012

Hafid Anwar, 2015. Peranan Tradis Lisan Sebagai Media Pembelajaran Pada Program Pemberantasan Buta Aksara dalam Lingkungan Komunitas Bajo Di Sulawesi Tenggara,,( Makalah: Disajikan pada Seminar Internasional dan Festival Tradisi Lisan IX, di Wakatobi, 12-15 Juni 2015)

Hafid Anwar dan Parman, 2015. Tradisi Lisan Suku Bajo (Pantun, Iko-Iko, Nauya, dan Mantra): Edisi ke 2. Kendari: Himpunan Sarjana Pendidikan Ilmu-Ilmu Sosial (HISPISI) Sultra.

Hafid Anwar. 2017. Peran Cerita Rakyat Iko-Iko Berbasis Sastra Melayu Dalam Penguatan Komunitas Etnis Bajo. Akses 12 Maret 2019.

Hatagalung, Sumitro. 2016. Pengaruh Kebudayaan terhadap Perilku Hidup Manusia.diakses tanggal 2 Maret 2016.

Sugiyono, 2005. Statistika untuk Penelitian, Bandung: Alfabetha.

Sugiyono, 2016. Metode Penelitian Pendidikan (Metode penelitian kualitatif, kuantitatif Dan kombinasi) .Bandung; Alfabeth.

Zuhdi, Susanto. 1997. "Sulawesi Tenggara dalam jalur Pelayaran dan Perdagangan Internasional Abad XVII-XVIII". Makalah disajikan dalam Seminar Nasional Sejarah dan Masyarakat Maritim di Kawasan September 1997.

Timur Indonesia. Kendari, 8-9 